\section{International Scientific Journal Theoretical \& Applied Science}

p-ISSN: 2308-4944 (print) e-ISSN: 2409-0085 (online)

Year: 2017 Issue: $11 \quad$ Volume: 55

Published: $30.11 .2017 \quad$ http://T-Science.org
Gulshad Gafurkhanovna Sharabitdinova

Lecturer

International Kazakh-Turkish University by name Yassavi, Kazakhstan

Aygul Tursunbekovna Suramisova Candidate of Medical Sciences Lecturer

International Kazakh-Turkish University by name Yassavi, Kazakhstan

SECTION 20. Medicine.

\title{
CLINICAL-EPIDEMIOLOGICAL CHARACTERISTICS OF TUBERCULOSIS OF THE CITY OF KENTAU
}

\begin{abstract}
We conducted a comparative analysis of the clinical structure of the incidence of tuberculosis. This analysis of the data showed a high incidence of tuberculosis in the lungs of the able-bodied population. In analyzing the clinical forms of tuberculosis in patients, it was demonstrated that the infiltrative form of tuberculosis ranks first. The epidemiological danger of tuberculosis of respiratory organs has significantly increased, which requires the activation of work on the active detection of tuberculosis and the conduct of preventive work among the population.

Key words: tuberculosis, clinical and epidemiological characteristics, comparative analysis of tuberculosis.

Language: Russian

Citation: Sharabitdinova GG, Suramisova AT (2017) CLINICAL-EPIDEMIOLOGICAL CHARACTERISTICS OF TUBERCULOSIS OF THE CITY OF KENTAU. ISJ Theoretical \& Applied Science, 11 (55): 272-276.

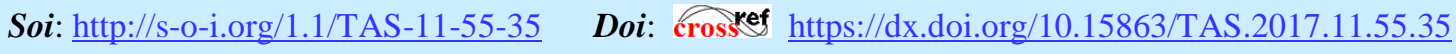

\section{УДК616.24-002.5-036.112}

\section{КЛИНИКО-ЭПИДЕМИОЛОГИЧЕСКАЯ ХАРАКТЕРИСТИКА ТУБЕРКУЛЕЗА ГОРОДА КЕНТАУ}

Аннотация: Нами было проведено сравнительный анализ клинической структуры заболеваемости туберкулеза. Данный анализ данных показал высокую заболеваемость туберкулезом легких трудоспособного населения. При анализе клинических форм туберкулеза у больных продемонстрировало, что на первом месте стоит инфильтративная форма туберкулеза. Значительно возросла эпидемиологическая опасность больных туберкулезом органов дыхания, что требует активизации работы по активному выявлению туберкулеза и проведении профилактической работь среди населения.

Ключевые слова: туберкулез, клинико-эпидемиологическая характеристика, сравнительный анализ туберкулеза.
\end{abstract}

АКТУльнОСТь: Туберкулез - это широко распространенное в мире инфекционное заболевание. По данным ВОЗ, около трети населения земного шара инфицировано микобактерией туберкулеза [1]. Туберкулез органов дыхания в настоящее время является одной из наиболее значимых медикобиологических и социально-экономических проблем. Проблема туберкулеза органов дыхания, находится в центре внимания медицинской науки и практического здравоохранения РК, так и во многих странах мира.
По данным экспертов ВОЗ, в мире ежегодно регистрируется более 10 миллионов новых случаев заболевания и около 3 миллионов летальных исходов, связанных с туберкулёзом $[2,3]$.

Неблагоприятные социальные и экономические условия жизни отдельных групп населения, а также обусловленная этими условиями социальная дезадаптация пациентов, нарушения и прерывания режима химиотерапии, отрывы от лечения и наблюдения создают благоприятные условия для формирования, размножения и распространения лекарственноустойчивых штаммов МБТ. При наличии 
исходной первичной множественной устойчивости МБТ наблюдается высокая вероятность хронизации туберкулезного процесса. Накопление неэффективно пролеченных больных с МЛУ МБТ способствует дальнейшему распространению возбудителя туберкулеза среди населения, инфицированию и новым случаям заболевания [4]. Так же наличие социальных факторов риска не оказывает влияние на клиническую форму заболевания, но повышает вероятность развития распространенных, деструктивных процессов с выделением МБТ и осложненного течения туберкулеза [5].

В связи с таким широким распространением туберкулёза встает вопрос о факторах риска заражения. Безусловным фактором является длительный семейный или производственный контакт с больным бактериовыделителем. Кроме того, можно выделить следующие факторы риска: мужской пол, возраст от 31 до 50 лет, сопутствующие хронические неспецифические заболевания лёгких, сахарный диабет, язвенная болезнь желудка и двенадцатиперстной кишки, наркомания, алкоголизм, бродяжнический образ жизни, психические заболевания, пребывание в местах лишения свободы [6].

Вместе с тем, клиническая структура заболеваемости продолжает ухудшаться отмечается ежегодное увеличение удельного веса распространённых деструктивных процессов с бактериовыделением, растёт число больных с остропрогрессирующим течением туберкулёза [7].

Утяжеление клинической структуры туберкулёза неблагоприятным образом отразилось на динамике показателя смертности, который в течение последних пяти лет колеблется на уровне 18,4-22,60/0000 и не имеет чёткой тенденции к снижению [8]. Настораживающим фактом является повышение летальности вновь выявленных больных, находившихся под наблюдением противотуберкулёзных учреждений менее одного года. Удельный вес туберкулёза в структуре смертности от инфекционных заболеваний в последние годы возрос до 70-85\% [9]. Основной причиной смерти таких больных является формирование полиорганной недостаточности, связанной с прогрессированием заболевания на фоне проводимого комплексного лечения [10].

ЦЕЛЬ ИССЛЕДОВАНИЯ: проведение сравнительного анализа возрастно-половой, социальной и клинической структуры заболеваемости туберкулезом органов дыхания.

МАТЕРИАЛЫ И МЕТОДЫ: Проведен сравнительный анализ 43 амбулаторных карт пациентов с туберкулезом в возрасте от 19-67 лет, выявленных за 10 месяцев 2017 года.

РЕЗУЛЬТАТЫ И ОБСУЖДЕНИЯ: В целях анализа основных характеристик эпидемического процесса туберкулеза (динамики заболеваемости, возрастной и половой структуры заболевших) проведен эпидемиологический анализ заболеваемости туберкулезом органов дыхания. По возрасту, разделены на 3 группы: 1-я возрастная группа - от 19 до 40 лет - 18(41,9\%) больных, 2-я возрастная группа от 41 до 60 лет $22(51,1 \%), 3-я$ группа старше 60 лет - 3(7,0\%) больных. Из них женщин - 26(60,5\%), мужчин 17(39,5\%) (таблица 1).

\section{Показатели заболеваемости туберкулезом с учетом пола и возраста}

Таблица 1.

\begin{tabular}{|c|c|c|c|c|c|c|c|c|}
\hline & \multicolumn{2}{|c|}{$19-40$} & \multicolumn{2}{c|}{$41-60$} & \multicolumn{2}{c|}{61 и старше } & \multicolumn{2}{c|}{ Всего } \\
\cline { 2 - 9 } & абс & $\%$ & абс & $\%$ & абс & $\%$ & абс & $\%$ \\
\hline Женщ. & 11 & 25,6 & 13 & 30,2 & 2 & 4,7 & 26 & 60,5 \\
\hline Мужч. & 7 & 16,3 & 9 & 20,9 & 1 & 2,3 & 17 & 39,5 \\
\hline Всего & 18 & 41,9 & 22 & 51,1 & 3 & 7 & 43 & 100 \\
\hline
\end{tabular}

Следует отметить, что контакт с больными туберкулезом легких отрицают - 27(62,8\%) пациента. Контакт с больными туберкулезом отмечают 14(32,6\%) пациентов, из них внутрисемейный - 2(4,7\%).
Рецидив туберкулеза отмечался у - 4(9,3\%) пациентов. Впервые выявленный туберкулез у 39(90,7\%) (рисунок 1). 


\begin{tabular}{|c|c|c|c|c|c|c|}
\hline Impact Factor: & $\begin{array}{l}\text { ISRA (India) } \\
\text { ISI (Dubai, UAF } \\
\text { GIF (Australia) } \\
\text { JIF }\end{array}$ & $\begin{array}{l}=1.344 \\
=0.829 \\
=0.564 \\
=1.500\end{array}$ & $\begin{array}{l}\text { SIS (USA) } \\
\text { PИНЦ (Russia) } \\
\text { ESJI (KZ) } \\
\text { SJIF (Morocco) }\end{array}$ & $\begin{array}{l}=0.912 \\
=0.207 \\
=\mathbf{3 . 8 6 0} \\
=\mathbf{2 . 0 3 1}\end{array}$ & $\begin{array}{l}\text { ICV (Poland) } \\
\text { PIF (India) } \\
\text { IBI (India) }\end{array}$ & $\begin{array}{l}=6.630 \\
=1.940 \\
=4.260\end{array}$ \\
\hline
\end{tabular}

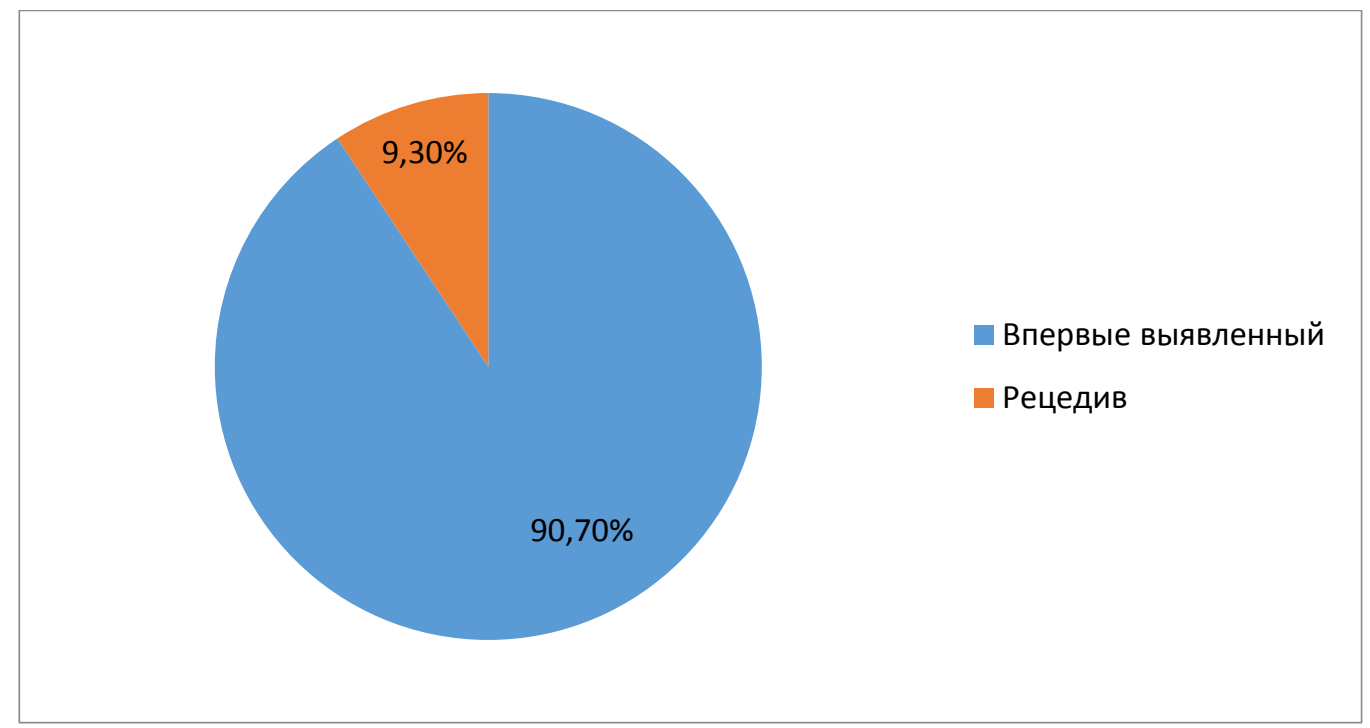

Рисунок 1 - Показатели впервые выявленного туберкулеза

Клиническая диагностика туберкулеза представляла определенные трудности, т.к. у большинства больных начало болезни было острым, только у 7 человек симптомы болезни нарастали постепенно в течение от 1 до 4-х недель. Лихорадка наблюдалась у всех больных. Также у большинства больных были выражены проявления интоксикационного синдрома: головная боль, нередко интенсивная с головокружением, выраженная слабость, артралгия и снижение аппетита. У части больных тошнота, рвота, боли в животе. Отмечались ознобы и обильная потливость, связанные с лихорадкой. При углубленном объективном исследовании органов дыхания удалось верифицировать туберкулез.

В клинической характеристике туберкулеза преобладает туберкулез легких $-41(95,3 \%)$, причем без бактериовыделения - 25(58,1\%). Внелегочный туберкулез встречается намного реже - 2(4,6\%) случая (рисунок 2$)$.

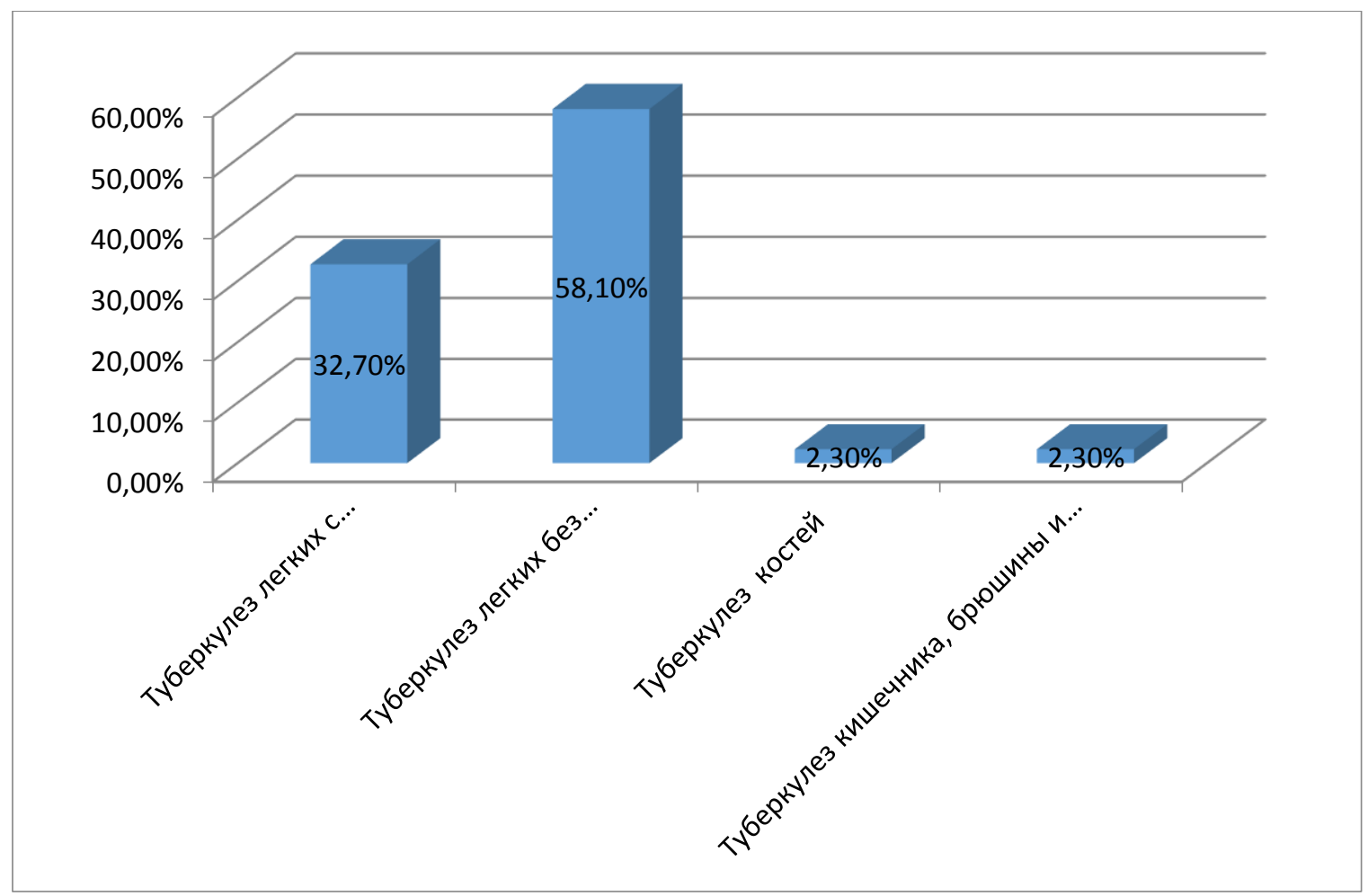

Рисунок 2 - Показатели клинических форм туберкулеза

ISPC Technological development, 


\begin{tabular}{|c|c|c|c|c|c|c|}
\hline Impact Factor: & $\begin{array}{l}\text { ISRA (India) } \\
\text { ISI (Dubai, UAF } \\
\text { GIF (Australia) } \\
\text { JIF }\end{array}$ & $\begin{array}{l}=1.344 \\
=0.829 \\
=0.564 \\
=1.500\end{array}$ & $\begin{array}{l}\text { SIS (USA) } \\
\text { PИНЦ (Russia) } \\
\text { ESJI (KZ) } \\
\text { SJIF (Morocco) }\end{array}$ & $\begin{array}{l}=0.912 \\
=0.207 \\
=\mathbf{3 . 8 6 0} \\
=\mathbf{2 . 0 3 1}\end{array}$ & $\begin{array}{l}\text { ICV (Poland) } \\
\text { PIF (India) } \\
\text { IBI (India) }\end{array}$ & $\begin{array}{l}=6.630 \\
=1.940 \\
=4.260\end{array}$ \\
\hline
\end{tabular}

Туберкулез легких с распадом встречается у 16(39,1\%), тогда как туберкулез легких без распада встречался у $25(60,9 \%)$ больных (рисунок
3). Все случае туберкулеза с распадом туберкулез легких с бактериовыделением.

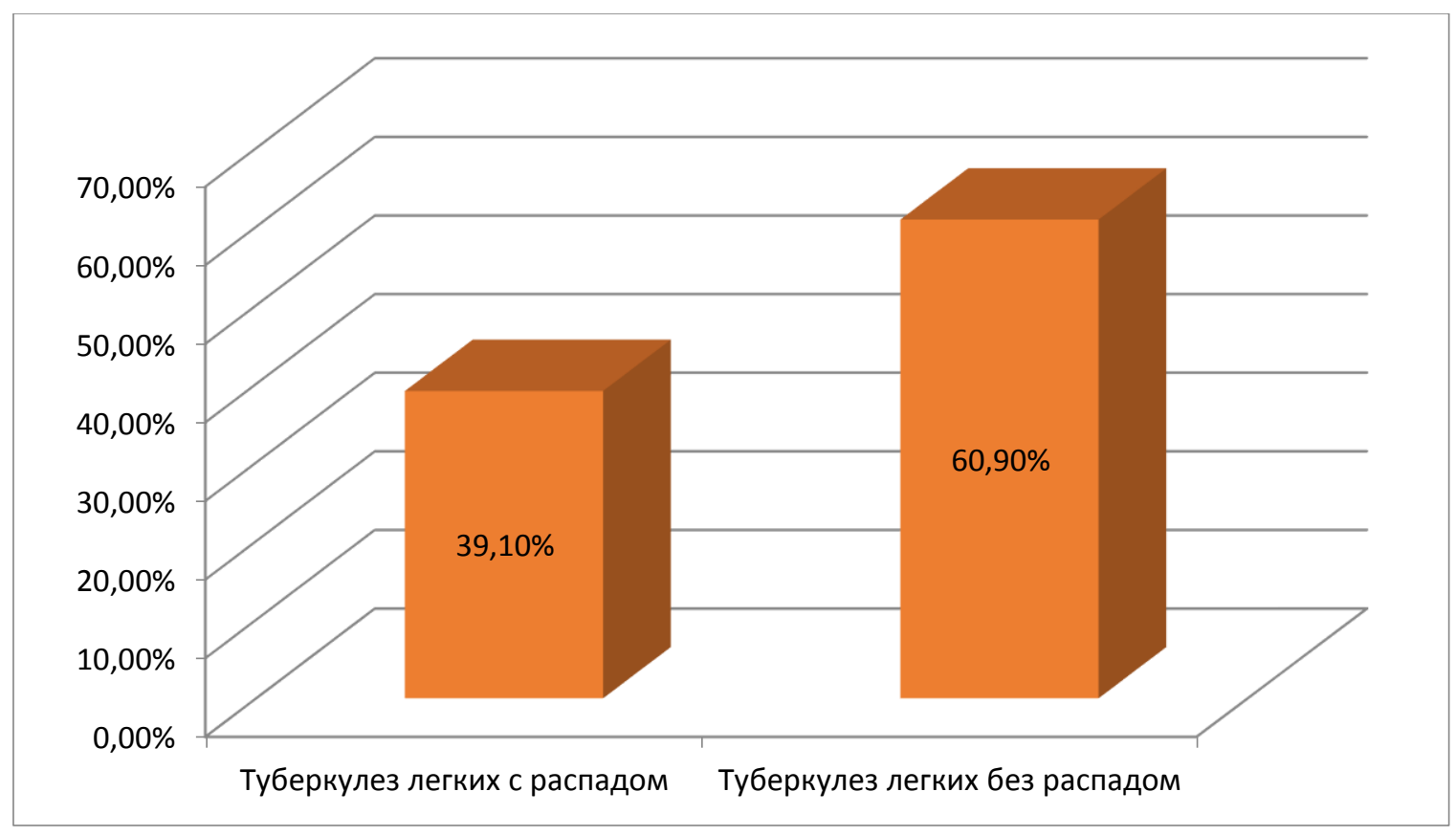

Рисунок 3 - Показатели клинических форм туберкулеза легких

Таблица 2.

Показатели сопутствующих заболеваний у больных с туберкулезом

\begin{tabular}{|l|l|l|}
\hline Сопутствующие заболевания & \multicolumn{1}{|c|}{ абс } & \multicolumn{1}{c|}{$\%$} \\
\hline Болезни легких (ХОБЛ, бронхиальная астма, хронический бронхит) & 6 & 26,1 \\
\hline Сахарный диабет & 2 & 8,7 \\
\hline ВИЧ инфекция & 4 & 17,4 \\
\hline Другие & 11 & 47,8 \\
\hline Всего & 23 & 100 \\
\hline
\end{tabular}

Сопутствующие заболевания выявлены у 23(64,4\%) больных (табл 2).

Различные заболевания органов дыхания в анамнезе зарегистрированы у $6(26,1 \%)$ больных, из которых наиболее часто встречались ХОБЛ, хронический бронхит, бронхиальная астма. Зарегистрирована 4(8,7\%) больных туберклезом у ВИЧ инфицированных больных. Из всех случаев туберкулеза легких $8(18,6 \%)$ - приведенные из других районов (больные работающие запределом области, приезжие на постоянное место жительство из других районов).

Так же туберкулез легких отмечался у беременных женщин 3(7,0\%).

\section{ВЫВОДЫ:}

1. Уровень заболеваемости туберкулезом органов дыхания среди женского населения ниже такового среди мужского населения на $21 \%$. По результатам сравнительного анализа максимальные значения заболеваемости туберкулезом органов дыхания у мужчин и у женщин приходятся на возраст от 41 до 60 лет 22(51,1\%) больных.

2. При анализе клинических форм туберкулеза органов дыхания у больных продемонстрировано, что на первом месте стоит инфильтративная туберкулез без бактериовыделения - 25(58,1\%), второе место туберкулез с бактериовыделением $16(32,7 \%)$ случаев, на третьем и четвертом месте внелегочный туберкулез.

Таким образом, возросшая эпидемиологическая опасность больных туберкулезом органов дыхания в современных условиях требует дальнейшего усиления работы по активному выявлению заболевания среди 


\begin{tabular}{l|lrl|l|ll} 
& ISRA (India) & $=\mathbf{1 . 3 4 4}$ & SIS (USA) & $=\mathbf{0 . 9 1 2}$ & ICV (Poland) & $=\mathbf{6 . 6 3 0}$ \\
Impact Factor: & ISI (Dubai, UAE) $=\mathbf{0 . 8 2 9}$ & PUHL (Russia) $=\mathbf{0 . 2 0 7}$ & PIF (India) & $=\mathbf{1 . 9 4 0}$ \\
& GIF (Australia) & $\mathbf{0 . 5 6 4}$ & ESJI (KZ) & $=3.860$ & IBI (India) & $=\mathbf{4 . 2 6 0}$
\end{tabular}

населения, и профилактическую работу, которая включает в себя как социально направленную профилактику, так и эпидемиологическую профилактику по более полному обследованию населения.

\section{References:}

1. Aksenova V.A., Sevostaynova T.A., Klevno N.I. (2013) Tuberkulyoz u detey i podrostkov v Rossii k nachalu XXI v. Vestnik roszdravnadzora. 2013. N3. 19-23.

2. (2002) Tuberkulyoz. Pod red. B.Bluma. - M.: Meditcina, 2002. 677.

3. (2015) Kliniko-epidemiologicheskaya harakteristika tuberkulyoa lyogkih легких. II mejdunarodnaya Nauchno-prakticheskaya konferentciya. Nauchniy jurnal "Globus", g. Sankt-Peterburg - 2015

4. Khudushina T.A., Voloshin E.P., Adamovich N.V., Maslakov M.G., Terekhova N.D. (2005) Lekarstvennaya ustoychivost mikobakteriy tuberkulyoza u vperviy viayvlennih bolnih tuberkulyozom lyogkih. Problema tuberkulyoza. 2005. № 12. 37-39.

5. Rashkevich E.E., Myakisheva T.V., Avdeeva T.G. (2011) Sotcialniye faktori piska i ih vliyanie na harakter i techenie tuberkulyoza $\mathrm{u}$ podrostkov. Sibirskoe meditcinskoe obozrenie. 2011. №6. 98-100.

6. Gelberg I.S., Wolf S.B., Avlasenko V.S., Pigalkova E.N. (2003) Vliyaniye faktorov riska na effektivnost' lecheniya bol'nykh tuberkulozom. Materialy 7 Rossiyskogo s"yezda ftiziatrov. - M., 2003. 243-244.

7. Levashov YU.N., Sheremet A.V., Grishko A.N. (2005) Tuberkuloz V Severo-Zapadnom Federal'nom Okruge. Probl. tuberkuloza.- 2005. № 11.3-6.

8. Mishin V.YU., Borisov S.Ye., Aksenova V.A., et al. (2005) Diagnostika i khimioterapiya tuberkuleza organov dykhaniya // Probl. tuberkuleza i bolezney legkikh. 2005. № 3. 4764.

9. Kerefova Z.SH. Makhova D.KH. Taasheva D.G. (2015) Kliniko-epidemiologicheskaya kharakteristika tuberkuleza legkikh. Nauchnyy zhurnal "Globus". Mul'tidistsiplinarnyy sbornik nauchnykh publikatsiy. Mezhdunarodnaya nauchno-prakticheskaya konferentsiya. g. Sankt-Peterburg. 2015. 30-34.

10. Nechayeva O.B., Arenskiy V.A., Vatolina V.A., et al. (2000) Smertnost' ot tuberkuloza v Sverdlovskoy oblasti // Probl. Tuberkuloz 2000. № 6. 36-39. 